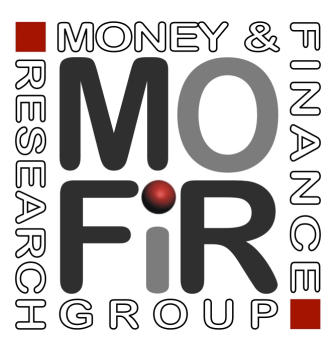

\title{
PROCYCLICALITY OF CREDIT RATING SYSTEMS: HOW TO MANAGE IT
}

\author{
Tatiana Cesaroni
}

Working paper no. 109

July 2015 


\title{
Procyclicality of credit rating systems: how to manage it
}

July 2015

\begin{abstract}
The recent Eurozone financial crisis has highlighted the need for stable rating systems to assess portfolio banks risks exposures abstracting from the current cyclical conditions.

This paper evaluates the characteristics of a Point in Time (PiT) rating approach for the estimation of firms' credit risk in terms of pro-cyclicality. To this end I first estimate a logit model for the probability default (PD) of a set of Italian non financial firms during the period 2006-2012, then, in order to address the issue of the rating stability (rating changes hedging) during the financial crisis, I study the effectiveness of an ex post PDs smoothing in terms of obligors' migration among rating risk grades. As bi-product I further discuss and analyze the role played by the rating scale definition (choice) in producing ratings stability.

The results show that an ex post PD smoothing is able to remove business cycle effects on the credit risk estimates and to produce a mitigation of obligors' migration among risk grades over time. The rating scale choice also has a significant impact on the rating stability. These findings have important policy implications in banking sector practices in terms of financial system stability.
\end{abstract}

Keywords: procyclicality, business cycle, financial stability, PiT rating system, long run probability default.

I'm very grateful to Stefano Neri, Lucia Esposito, Riccardo De Bonis, Luigi Cannari, and Francesco Palazzo for their useful comments and suggestions to a previous version of the paper. I also thank the participants to Bank of Italy lunch seminar held on January 29, 2015 and an anonymous referee for their comments. I finally thank Antonietta Mendolia and Giuseppina Papadia for the help with the data acquisition from Central Credit Register database. The opinions expressed are those of the author and do not represent the views of the Bank of Italy. Any error or mistake remains the author's sole responsibility. 


\section{Introduction}

The deep economic and financial crisis that has recently affected many European countries has faced the problem of building up reliable credit rating systems to evaluate the degree of banking sector exposures and the financial risks in the Euro Area. To this purpose, the possibility of using banks portfolio rating methodologies looking to a long term view instead of short run has been discussed in different contexts; the most known concerns the current debate on the role of rating agencies in producing credit risk default assessments able to take into account the effects of business cycle phases on obligors' creditworthiness.

This study contributes to such important debate by describing and analysing the issue of setting up a rating system to estimate banks portfolio credit risk that takes adequately into account of business cycle conditions. More in detail it assesses both theoretically and empirically the consequences of possible intervention measures into such framework, aimed to reduce rating procyclicality (and gain financial stability), in terms of rating consistency and accuracy.

A credit rating system can be defined as a procedure that assigns an individual Probability Default (PD) to each obligor on the base of its financial soundness and/or the general macroeconomic conditions through a model and/or a set of rules. Obligors with similar individual PDs are then grouped (or mapped) into an ordinal rating scale consisting of different rating grades (or risk buckets) through a given function (or mapping algorithm). An average pooled PD is finally assigned to all the obligors sharing the same rating grade.

In monitoring a bank portfolio credit risk two main rating philosophies can be taken into account: the so-called Point in Time (PiT) and "Through the cycle (TtC)" approaches. A PiT rating system produces, as known, an obligor Probability Default that is countercyclical and associated to macroeconomic short run variations. It means that the estimated obligor Probability Default (PD) will increase during recessions and decreases during expansions. The use of PiT PD can thus possibly amplify the pro-cyclicality of the credit market and more in general of the financial sector. A TtC rating approach, quite the opposite, produces a smoothed PD obtained removing the cyclical factors in the data. ${ }^{1}$ The smoothed PDs, reflects in this way a long run credit risk profile of firms (obligors) and it appears more stable and less volatile over time. In this respect the building up of TtC rating systems to evaluate obligors' default (considering a long run perspective), would allow to avoid undesirable pro-cyclical effects on the banking and financial sectors due to business cycle.

\footnotetext{
${ }^{1}$ The smoothing techniques usually applied are based on moving averages or judgmental procedures.
} 
Although many banks and rating agencies already use a $\mathrm{TtC}$ perspective in evaluating probability defaults, in the Basel Regulatory framework ${ }^{2}$ and more in detail within the Eurosystem credit assessment framework (ECAF) ${ }^{3}$, a clear definition of what perspective a rating system should adopt in measuring PD associated to the obligors is not given and both PiT and TtC rating approaches are allowed. ${ }^{4}$

With regard to the rating philosophy choice, it is important to notice that while from a bank risk management perspective the use of a PiT rating would ensure a better credit risk assessment, from a central bank monetary policy and macroprudential view a TtC approach would produce better results in terms of countercyclical monetary policy objectives and financial system pro-cyclicality containment. The central bank monetary policy operations are in fact based on the amount of financial assets eligible as collateral ${ }^{5}$ that eventually depends on portfolio credit rating philosophy adopted as well as the macroprudential policies aimed to reduce procyclicality that are based on TtC financial reporting and risk measurement.

In a TtC rating philosophy, PD estimates are supposed to reflect a "long-run average”, i.e. an average PD over both economic expansions and recessions ${ }^{6}$. In this view the average PDs assigned to the obligors by the mapping algorithm are free from short run variations and more stable over the years. However, in dealing with $\mathrm{TtC}$ ratings we should keep in mind the trade off between the loss of predictive ability due to the estimation with a $\mathrm{TtC}$ model of the true default rates that are PiT and the stability of ratings over time.

Indeed credit cycle is strongly linked to business cycle due to the fact that credit flows increase during expansionary periods and decrease during recessions. Analogously, the default rate data on obligors are also affected by business cycle fluctuations and thus are PiT. Consequently the econometric models used to predict the borrowers probability default (i.e. logit, probit models, or panel models) over one year horizon are usually PiT since they also contain the effects of the economic cycle. As a result, the predictive power of the true default rate is very high but, the predicted PDs assigned to each risk bucket by the mapping algorithm, depending on the state of the

\footnotetext{
${ }^{2}$ BIS (2010) Basel Committee on banking supervision Guidance for national authorities operating the countercyclical capital buffer.

${ }^{3}$ The ECAF is a set of procedures, rules and techniques defined within the Eurosystem in order to achieve high credit standards for all the eligible assets within the Eurozone.

${ }^{4}$ Within the ECAF four main credit assessment instruments are used, namely ECAI, IRB, Rating Tools and ICAS. Some of them use PiT perspectives while some others are more in line with a TtC view. This heterogeneity in the obligors creditworthiness assessment can create incoherence in comparison exercises among various credit assessments tools (i.e. benchmarking).

${ }^{5}$ If the PD increases the effect on the amount of collateral pledged in the Eurosystem credit assessment framework is to reduce the quantity of eligible collateral, while if $\mathrm{PD}$ decreases the effect is an increase.

${ }^{6}$ The detection of $\mathrm{TtC}$ credit risk estimates free from cyclical fluctuations is not easy since as documented in Cesaroni et al (2011) the length of a business cycle changes over time and the duration of expansionary and recessionary phases is asymmetrical and even changes over time.
} 
economy, will vary considerably producing sometimes unnecessary fluctuations of obligors among risk buckets over time. ${ }^{7}$

To limit such fluctuations, a possible solution can involve the use of an ex post correction to PiT estimated default rates. For example, by applying a constant to rescale the PDs we can obtain smoothed PDs more in line with a TtC rating view. Another possibility would involve the use of robust risk buckets with an interval length able to limit excessive obligors' swing among buckets.

Given the relevance of pro-cyclicality treatment and assessment into PiT ratings this paper focuses on two objectives. First, it considers the use of countercyclical scaling factors to produce $\mathrm{TtC}$ credit ratings and evaluates the stability of the results in terms of obligors' migration among risk classes. Second it assesses the role played by rating buckets detection (i.e. risk buckets built using cluster analysis versus fixed risk buckets) in determining rating stability.

Paragraph 2 analyses the main causes and consequences of procyclicality in the financial system. Paragraph 3 describes the data set and introduces the econometric default probability model. Paragraph 4 discusses the rating trade off between accuracy and stability and formalizes it into TtC and PiT ratings systems. Paragraph 5 evaluates the impact of the ex post PD smoothing in terms of obligors migrations over years and among risk classes and assesses the role of the rating scale definition on the rating stability. Conclusions follow.

\section{2) Main causes of procyclicality in the overall financial system and in the financial regulatory framework.}

\subsection{Procyclicality in the financial system}

The procyclicality of financial institutions and banks systems is mainly linked to their lending activity. In expansions periods banks can underestimate their risk exposure, relaxing obligors' selection criteria and reducing their capital buffers. Quite the opposite, during recessions a greater exposure to credit risk can determine a contraction of banks assets through a reduction of granted credit lines. Since this mechanism determines an increase in credit supply during expansion phases and a reduction during recessions, it can potentially contribute to amplify cyclical fluctuations instead of counterbalance them. As well documented in seminal works (Kashyap, 2005 and Lowe, 2002) even if the financial system and consequently credit flows procyclicality can be considered physiological (it mainly arises from the idiosyncrasy between banks funding and

\footnotetext{
${ }^{7}$ The PiT rating philosophy can also be to a certain extent amplified by a Traffic light approach based on a backtesting mechanism with an annual view.
} 
lending, asymmetric information, herding behaviour etc.), it should be adequately treated in order to avoid excessive swings of economic fluctuations and the occurrence of systemic risks.

\subsection{Procyclicality in the current financial regulatory framework}

To ensure financial stability, the measures adopted into the financial regulation framework over the last years had as main objective the control of possible systemic risks and contagion effects. The two main reforms that in the last years contributed to introduce risk control elements into the banking sector are the adoption of the International Accounting Standards (IAS 39) principles in 2005 and the so called Basel 2 directive on capital requirements introduced by the Committee on Banking Supervision in 2006. Both measures, although introduced to prevent risks related to the banking system, contain features that possibly may intensify the financial system procyclicality. $^{8}$

The main cause of pro-cyclicality in the Basel 2 framework is the regulation on the banks minimum capital requirements. Basel 2 Capital accord links the minimum capital requirement to the portfolio riskiness. In this framework business cycle produces effects both on the absolute level of capital owned by the bank (as in the previous Basel I directive), and on the variation of its assets riskiness measured on obligors’ rating among different rating classes. Since the obligors' migration among grades depends on their creditworthiness but also on the general macroeconomic conditions, an obligor mapping based on a PiT rating system can produce an increase of the downgrading frequency in case of economic conditions deterioration.

To take into account this shortcoming Basel 2 accord has introduced the possibility of using TtC rating approaches into the banks rating systems. With this mechanism the individual PiT PDs assigned to each obligor ${ }^{9}$ can be corrected using smoothing techniques based on long run moving averages (at least five years, and in each case possibly an entire business cycle) in order to reduce their volatility.

Another regulation element that can potentially trigger pro-cyclicality into the financial system is the adoption of fair-value accounting (so called market value) for the evaluation of all financial activities introduced with the implementation of the International accounting standards (IAS 39). From one hand the introduction of fair value allows to obtain a greater transparency with respect to the historical cost criterion, from the other hand it can introduce volatility in income,

\footnotetext{
${ }^{8}$ To address the regulation drawbacks emerged during the 2007 crisis, the regulatory framework has furthermore received modifications that brought to Basel 3 introduction and to a further revision of IAS 39 principles that are both still in phase of implementation.

${ }^{9}$ The use of $\mathrm{TtC}$ rating is not binding and its implementation depends on banks decision.
} 
profits as well as into the budget balance items because the assets evaluation is linked to short run market movements.

Given the drawbacks of pro-cyclicality in the financial system, a strand of literature has been devoted to analyze and develop TtC credit rating systems. To this end Nickell et al (2001) estimate obligors rating using a probit model and analyze the stability of ratings with respect to obligors sector type country and business cycle in terms of transition matrix migrations. Analogously Bangia et al (2002) analyze the issue of credit risk procyclicality considering credit migration matrices free from business cycle conditions. By conditioning the migration matrix on two states of the economy (expansion and contraction), they show that the loss distribution of credit portfolios can differ significantly over the business cycle. D’amato and Furfine (2003) study the degree of procyclicality of the ratings produced by Standard \& Poors using annual data on US firms and conclude that there is little evidence of procyclicality in their ratings. Loffler (2004) analyze the properties of TtC rating methodologies used by the main rating agencies using a market value model of default (i.e. a Value at Risk model) and concludes that TtC rating is more stable than PiT. To do this She separates transitory and permanent components in default frequencies of rating agencies using Kalman filter techniques. Valles (2006) estimates the probability default for a set of Argentinian obligors using a probit model and produces a TtC rating developing “stable risk buckets” obtained through cluster $\mathrm{k}$ means methods in order to minimize the Chi square criteria.

Kiff, Kisser and Schumacher (2013) study the TtC rating properties in terms of accuracy and stability. They consider a market value approach to the risk default estimation and analogously to Loeffler decompose the asset value of a firm in permanent and transitory components.

This paper extends the previous literature on the rating procyclicality discussing and analyzing the possible intervention solutions into a PiT rating in order to produce PDs in line with a TtC rating view. To this end I use a dataset of Italian banks' borrowers built taking information from Bank of Italy Central Credit Risk Register and the Company Account Register. Indeed, the main advantage of using a $\mathrm{TtC}$ rating system is to take into account long run dynamics in the economy through the restraint of business cycle impact on the probability default estimates and to the last analysis on the overall amount of credit available into the banking system.

\section{3) The dataset and the logit model}

In order to evaluate the characteristics of a PiT rating system in terms of procyclicality, I consider microdata of non financial sector obligors default (adjusted bad loans) coming from Bank of Italy Central Credit Register (CR) and Italian Balance sheet database (CEBI CERVED). More in detail I use the one year default probabilities of non financial firms' obligors at the end of each year 
and having an overall exposure versus the banking system greater than 75000 euros. The default definition is based on the nonperforming loans. According to this definition an obligor is considered in default if it is unlikely that the obligor will repay its bank debt and the obligor is in past due from more than 90 days. Furthermore, the default definition used is "system wide" meaning that it considers the exposure of a given obligor versus the whole banking system and not only with respect to a single bank. In this respect the rating assigned to the obligor is versus the system and not with respect to a given lender bank. The data spans from 2006 to 2012.

The database has a changing number of observations year to year because there are some obligors registered in December of a given year that are not present at December of another year.

To provide a first descriptive analysis of the data, table 1 reports the unbalanced panel of the total debtors and the share of them resulting in default at the end of the year together with yearly GDP growth and spreads over the sample 2006-2012. Looking at the default rates dynamics over the years (column 4) we can notice a peak corresponding to 2009. GDP growth is negative in 2008 and 2009 corresponding to the economic crisis. In 2012 GDP growth also registers a negative growth although less pronounced with respect to 2009. Looking at the spreads we also can notice an increase of short and long term interest rates differentials starting from 2009.

Table 1: Panel data description

\begin{tabular}{|lccccc|}
\hline Period & Debtors* & $\begin{array}{c}\text { Default* } \\
\text { debtors }\end{array}$ & $\begin{array}{c}\text { Default } \\
\text { rate }(* 100)\end{array}$ & $\begin{array}{l}\text { GDP } \\
\text { growth }(* 100)\end{array}$ & Spreads \\
\hline 2006 & 205508 & 1541 & 0.75 & 2.20 & 0.97 \\
2007 & 223321 & 1267 & 0.57 & 1.68 & 0.21 \\
2008 & 243401 & 1385 & 0.57 & -1.16 & 0.05 \\
2009 & 257961 & 2448 & 0.95 & -5.49 & 3.08 \\
2010 & 266193 & 2251 & 0.85 & 1.70 & 3.23 \\
2011 & 270201 & 2081 & 0.77 & 0.5 & 4.03 \\
2012 & 268263 & 2147 & 0.80 & -2.5 & 4.92 \\
\hline
\end{tabular}

*source Credit Register

The credit risk model used to estimate and forecast Italian non-financial firms' portfolio default probability is a logit. ${ }^{10}$ The estimated independent variable is the default it $d$ of a given firm taken from Credit Register. The default takes a value of 1 if the obligor is in default at the end of the year default definition conditions and 0 otherwise. The model takes the form:

\footnotetext{
${ }^{10}$ There exist several ways to model default rates. Since in this context the dependent variable y shows a very low variability over time I choose to model the population of banks obligors using a pooled logit.
} 


$$
\log \left(\frac{P D_{i}}{1-P D_{i}}\right)=\beta_{0}+\sum_{j=1}^{k} X_{i t j}+\varepsilon_{i j t}
$$

where $P D_{i}$ represents the probability that firm $i$ will fail and 1- $P D_{i}$ represents the probability that firm will not fail. $X$ is a set of explanatory variables containing firms' budget data, financial data and macroeconomic data. ${ }^{11}$

The explanatory variables can be divided into two groups: (i) financial variables related to the firms' structure changing over time and over individuals (dimension it) coming from Italian Central Credit Register and from firms' balance sheet (ii) macroeoconomic variables (t dimension) that account for business cycle changes over time.

The first group includes:

- The drawn amount on granted amount (creditdr) by firms is a proxy of creditworthiness. The expected sing on PD is positive (Source: Credit register).

- Number of overdrawns in last five end quarters (overdr). This indicator represents a proxy of the firms' probability of default because the higher is the number of overdrawns the higher is the PD of a given firm (Source: Credit register).

- Net financial expenditures/EBITDA (finexp). This indicator captures the firm financial soundness. (Source: Balance sheet).

- Age of firm (age): The expected sign is negative because an higher number of firm survival years on the market will reduce the expected firms default. (Source: Credit register).

The second group includes:

- GDP_Growth: this variable captures the effects of business cycle over the economy on the probability default of a given obligor. The expected sign on PDs is negative.

- Spreads: They are built as yearly long term minus short term interest rates. This variable, reflecting the market expectations, allows to take into account although indirectly the international environment. ${ }^{12}$ The expected sign is positive because the higher is the differential between long term and short term interest rates the higher will be the expected PDs.

\footnotetext{
11 The model could also include a more complete set of financial firms indicators. However the model specification is not the focus of the paper and it is functional to the procyclicality treatement.

${ }^{12}$ The differential between long term and short term interest rates reflects to some extent the market expectations on a country ability to repay its debts. In this sense represents a market based proxy of the default probability.
} 
Table 2 logit model over the period 2006-2012.

\begin{tabular}{|lcrr|}
\hline Log likelihood = -59118.047 & & \multicolumn{2}{c|}{ Pseudo R2 $=$} \\
default & Coef. & Std. Err. & \multicolumn{1}{c}{ z } \\
\hline gdpgrowth & -1.53013 & 0.3534616 & -4.33 \\
spread & 0.09497 & 0.0055983 & 16.96 \\
creditdr & 4.21953 & 0.0885666 & 47.64 \\
finexp & 0.00492 & 0.0001741 & 28.26 \\
overdr & 0.76247 & 0.0054289 & 140.45 \\
age & -0.01156 & 0.0009227 & -12.54 \\
cons & -10.5609 & 0.0844931 & -124.99 \\
LR chi2(6) $=36074.42$ & Prob $>$ chi2 $=0.0000$ Number of obs $=1734830$ & \\
\hline
\end{tabular}

Table 2 reports the estimated logit model over the period 2006-2012. The variables were selected on the basis of their economic relevance and statistical significance. The Number of Observation is 1734836. All the coefficients are significant at $1 \%$ level. Looking at the coefficient signs we can notice that as expected a negative relationship between business cycle and default rate. The spread is also significant and enters with the expected sign of the coefficient. FINEXP and the number of overdrawn account for an increase in default probability, quite the opposite the Age of firm enters in the equation with a negative sign.

Table 3 Measures of model discriminatory power

\begin{tabular}{|c|c|}
\hline Year & Accuracy Ratio (AR) \\
\hline 2006 & 0.90 \\
\hline 2007 & 0.91 \\
\hline 2008 & 0.91 \\
\hline 2009 & 0.90 \\
\hline 2010 & 0.90 \\
\hline 2011 & 0.90 \\
\hline 2012 & 0.90 \\
\hline
\end{tabular}

To validate the model (i.e. distinguish if the model correctly discriminates between defaulted and not defaulted obligors) table 3 reports the Accuracy Ratio (AR) statistics by year. The AR curve accounting for the percentage of times in which the model is able to predict the true default ranges from 0.90 to 0.91 showing a very good discriminatory power of the model. 


\section{4) Rating Trade off between accuracy and stability}

In setting up a reliable rating system on the one hand we would like to obtain a credit risk model able to correctly predict obligors' default, on the other hand we would like avoid an excessive variability in the obligors classifications into the risk buckets of the rating scale over the years. We are hence vis à vis with a trade off between accuracy and stability.

A desirable feature of a rating system in fact is not only its predictive ability but also the capacity to obtain a stability of obligors’ migration among risk categories and over time.

A PiT rating usually has a good predictive power but can potentially amplify obligors' migration among risk categories. A TtC rating, quite the opposite, displays a lower predictive ability but can improve the rating stability.

The building up of a stable rating system would have the advantage of reduce financial system procyclicality and would contribute to counterbalance business cycle effect on banking system.

A credit rating system can generally be affected by pro-cyclicality through the estimated PD itself that are PiT. This feature determines a migration of firms among Credit Quality Risk buckets over years that is to a certain extent affected by the effects of economic cycle and can potentially amplify pro-cyclicality. Besides, the length of the intervals defining the risk buckets of the rating scale also plays a role in determining the rating stability because closer intervals increase the probability of obligors’ migration among risk classes over time.

In order to assess and compare the characteristics of $\mathrm{PiT}$ and $\mathrm{TtC}$ ratings in terms of stability, in what follows I set up a possible formal definition of a PiT rating and of two alternative TtC rating definitions. The first one is based on a PD smoothing. The second one is based on a robust risk buckets definition.

Definition 1 A PiT rating system is defined by (1) a function $f$ assigning a PD to each obligor on the basis of macroeconomic conditions and its financial soundness information (2) A rating scale consisting in a discrete set of rating grades (or risk buckets) (3) A mapping algorithm that assigns each obligor to a given rating grade.

Definition 2 A TtC rating system is defined by a (1) function f assigning a PD to the obligors on the basis of macroeconomic conditions and its financial soundness information (2) An ex post smoothing to remove cyclical factors from the estimated PDs (3) A rating scale consisting in a 
discrete set of robust rating grades (or risk buckets) (4) A mapping algorithm that assigns each obligor to a given rating grade.

Definition 3 A TtC rating system is defined by a (1) function $f$ assigning a $P D$ to the obligors on the basis of macroeconomic conditions and its financial soundness information (2) A rating scale consisting in a discrete set of robust rating grades (or risk buckets) (3) A mapping algorithm that assigns each obligor to a given rating grade.

In a rating system we can thus improve the stability acting on PD smoothing, rating grades definition or a combination both.

Proposition 1 Assume a fixed rating space $S=\left(R_{1}, R_{2}, \ldots . R_{k-h}, \ldots, R_{k-1}, R_{k}\right)$ with probability intervals $(j ; j+m)$ defining each risk bucket $R_{k-h}$, then the probability of migration from bucket $R_{k-h}$ to bucket $R_{k-l}$ of obligor $j$ in switching from an expansion (recession) to a recession (expansion) will be higher (lower) for PiT PD than for TtC PD.

\section{(See proof in the appendix)}

The intuition for the above result follows from the fact that at firm level PIT PD displays an higher variability over time w.r.t. a smoothed TTC PD by definition. This fact, under a recession determines an increase of PD over time greater than under a TTC rating. This would produce a greater firms migrations in the highest buckets (worst obligors) over recessions and to the lowest buckets (best obligors) during expansions because it will be more common to have an estimated PD in $t$ that overpass the risk bucket from $t$ (i.e expansion) to $t+1$ (i.e. recession).

Proposition 2 Assume a fixed rating space $S=\left(R_{1}, R_{2}, \ldots . R_{k-h}, \ldots, R_{k-1}, R_{k}\right)$ with probability intervals $(j ; j+m)$; assume a more granular rating space $S^{*}=\left(R_{1}, R_{2}, \ldots . R_{k^{*}-h}, \ldots, R_{k^{*}-1}, R_{k^{*}}\right)$ with $R k^{*}>R k$, and $\left(k^{*}-h\right)<(k-h)$ for each $R$, the Probability of migration from bucket $k^{*}-h$ to bucket $k^{*}-l$ of obligor $j$ over time will be higher under $S^{*}$ compared to $S$ for both PiT and TtC PD rating philosophies.

\section{(See proof in the appendix)}


Intuitively, the above result reflects the fact that shorter risk buckets will display lower probability thresholds and thus the frequency of overpassing that PD bucket from $t$ to $t+1$ will be higher under $S^{*}$.

On the basis of the above definitions and propositions in what follows, we evaluate the removal of the pro-cyclicality effects in a PiT rating system, both applying an ex post PD smoothing and considering robust risk bucket thresholds. With the first approach PDs cyclical factors are removed applying a scaling factor (varying over years) making an ex post correction of PD PiT at firm level. The resulting obligors PDs being in line with those obtained with a through the cycle rating allow to control for business cycle effects on obligors defaults migration among rating grades. With the second intervention measure we consider robust risk buckets with thresholds accounting for lower PD variability over time. In this case the buckets are detected endogenously to the model through cluster analysis techniques.

\section{Ex post $P D$ smoothing}

Let the probability default of a firm $i$ at time $t$ be $P D_{i}(t)$ with $0<P D_{i}(t)<1$. Let $S=\left(R_{1}, R_{2}, \ldots . R_{k-}\right.$ ${ }_{h}, \ldots, R_{k-1}, R_{k}$ ) be the rating space and $R_{1}, . . R_{k}$ the risk buckets (or rating grades) defining of the rating scale. Each risk bucket $(R)$ is represented by a probability interval $(j ; j+m)$ with $0<j<1,0<j+m<1$. The former risk buckets will correspond to the lowest probability default and thus will include the best obligors.

Let $N(t)$ be the number of rated firms in a given year $t$ and $n(t)$ be the number of true defaulted firms in $t$. The scaling factor can be computed as:

$$
S F(t)=D R \_L R(t) / D R(t)
$$

where $D R(t)$ is the current default rate in t given by $n(t) / N(t)$ and $D R \_L R(t)$ is its long run average. The calibration produces a new weight for the probability default at firm level in each year $t$ obtained applying the corresponding scaling factor:

$$
P D^{T T C}(t)=P D^{P I T}(t) * S F(t)
$$


where $P D_{i}(t)$ is the probability default of a given firm in $t$ and $P D_{i}^{T T C}(t)$ is the corresponding TtC correction, obtained by multiplying the PD at firm level with the scaling factor. In expansion periods the $S F(t)$ will be greater than 1 and will increase the $P D_{i}^{T T C}(t)$ of the obligors. In recession periods the $S F(t)$ will be less than 1 and will reduce the $P D_{i}^{T T C}(t)$ of the obligors. The countercyclical pattern of $S F(t)$ allows to smooth business cycle effects on PDs.

The scaling factor (SF), given by the ratio of the long run default component for the total amount of obligors and the current total default rate can be applied to the estimated obligors PDs at firm level coming from a PiT model. By multiplying the estimated PD at firm level with the SF, the predicted estimated PDs would be more in line with a $\mathrm{TtC}$ approach.

To explain the effects of PDs smoothing on the mapping algorithm consider fixed risk buckets thresholds; the mapping algorithm (MA) that assigns an obligor $i$ at time $t$ to a given risk bucket under a PiT rating will be represented by the following function:

$$
F_{K-H}\left(P D_{i}\right)_{i}^{P I T}(t)=1 \quad \text { if }\left(j<P D_{i}^{P I T}(t)=<j+m\right) \text { and } 0 \text { otherwise }
$$

In case of smoothing the mapping function will be the same but the argument will be $P D_{i}^{T T C}(t)$.

$$
F_{K-H}\left(P D_{i}\right)_{i}^{T T C}(t)=1 \text { if } \quad\left(j<P D_{i}^{T T C}(t)=<j+m\right) \text { and } 0 \text { otherwise }
$$

Or equivalently:

$$
\underset{K-H}{F}\left(P D_{i}\right)_{i}^{T T C}(t)=1 \text { if }\left(j<P D_{i}^{P I T}(t) * S F(t)=<j+m\right) \text { and } 0 \text { otherwise }
$$

Overall a scaling factor $S F(t)$ less than 1 will reduce the obligors PDs and thus will increase the number of firms in the lowest risk buckets (in which are put "the best obligors"). A scaling factor greater than 1 will work in the opposite direction. Namely, it will determine higher individual PDs and thus it will reduce the number of firms into the lowest rating classes and will imply a migration of obligors in the highest risk buckets.

It is important to notice that from a theoretical point of view since the true realized PDs are PiT the backtesting should be also conducted on PD PiT without business cycle correction. Once 
that the model is able to pass the backtesting ${ }^{13}$, the scaling factor correction should exclusively have as a task the smoothing of business cycle effects of obligors migrations among classes. The ex post correction would allow to conduct the usual model diagnostics on the PiT model and to make an ex post adjustment of obligors in order to avoid excessive obligors variability over the risk categories in the wake up of mapping gaining stability improvements. ${ }^{14}$

\section{Risk Buckets length and rating stability}

Another possibility to manage pro-cyclicality is to act on the risk buckets length. ${ }^{15}$ A larger length of buckets for example, could determine an higher concentration of the obligors only in few buckets reducing the possibility to differentiate changes the obligors creditworthiness.

A Mapping towards larger risk buckets would determines an higher migration of the obligors in the better risk categories during recessions compared to shorter risk buckets but at the same time wouldn't guarantee a proper granularity of the intervals that is a desirable property of a rating system. An optimal solution would require the selection of robust risk buckets determined in order to achieve a desired tradeoff between stability of obligor migrations over time and accuracy (namely, possibility to appropriately differentiate the obligor creditworthiness among rating grades). A possibility to detect risk buckets robust to cyclical fluctuations is to determine them endogenously to the model by partitioning the estimated PDs through cluster techniques (See Foglia et al, 2001 and Valles, 2006). This intervention measure displays advantages and disadvantages; on the one hand allow to estimate risk buckets consistent with the obligors pool analysed but on the other hand h do not allow a comparison with other ratings evaluated on different other obligors pools.

\section{5) Empirical results}

In what follows we analyze the impact of the PD smoothing and the rating scale definition on the non-financial firms' portfolio rating stability (and thus on the pro-cyclicality mitigation). To do this is to assess the effects of the two methodologies in terms of obligors' migrations among risk classes.

\footnotetext{
13 In this context the backtesting is meant as a procedure used to validate the results of the rating model in terms of pooled PDs. It operates through a comparison of the average PD in each rating grade with the true realized default rate.

14 The correction of a PiT PD estimates can be made using a scaling factor that can correct the cyclical factors in line with the production of a TtC approach. Such a constant can be considered a sort of a weight that can rescale the estimated PD at obligor level.

${ }^{15}$ Larger interval length will determine a lower probability of obligors' migration among risk buckets over time.
} 


\subsection{Effects of PD smoothing on the rating stability}

The removal of PD cyclical components to detect its long run behavior can be obtained using the same time series techniques applied for detrending purposes (moving averages, HP filters, unobserved component models, polynomial detrending ect.). In the paper, given the yearly frequency of the data and the short sample length (7 years), I apply a simple mean of default rates over the period. ${ }^{16}$ The ratio between the mean and the current default rate represents the scaling factor (SF_mean). To perform a sensitivity analysis I also compare the results with a smoothing that considers the maximum default rate of the sample as the long run default rate component (SF_MAX). ${ }^{17}$ Using these two long run default values both of them corresponding to possible long run view of default rates, we can built two countercyclical scaling factors. Obviously, the scaling factor based on the maximum default rate (bottom PD hypothesis) ${ }^{18}$ will give more conservative results in terms of backtesting by construction with respect to the scaling factor based on the average default rate.

To give an intuition of the differences in applying the two hypothesis of long run defaults Graph 1 reports a comparison between the annual default rates and the two long run components definitions used to built the scaling factors: $D R \_L R(t) \_$mean and $D R \_L R(t) \_m a x$. The first one based on the average default rate over the period (DR_LR(t)_mean), the second one considering the maximum default rate over the period (DR_LR(t)_max).

Graph 1 Comparison between current default rates average and maximum default rates.

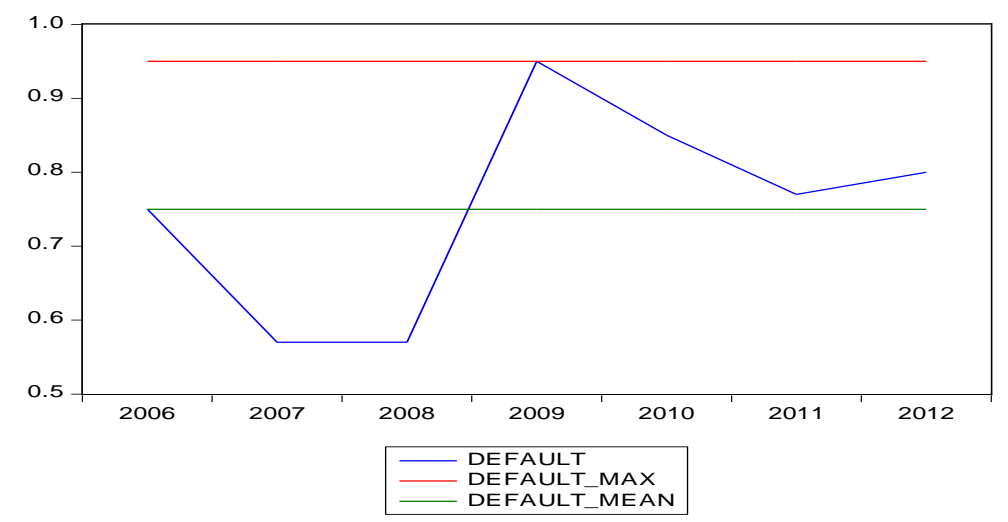

\footnotetext{
16 The choice of a smoothing based on the average of yearly data gives more consistency to the analysis since I consider the same data frequency that I use in the paper for the model estimates. In banking practice another possibility would be to use quarterly default rates from CR and to estimates the Scaling factors on the basis of higher data frequency (i.e. use of last quarter scaling factor for a given year) however the results are quite similar.

17 This hypothesis can be considered analogous to the Wharton school method for the degree of plant utilization estimation that takes the maximum value of the capacity utilization in a sample as its long run component.

18 The scaling factor is built considering as long run default rate the maximum peak over the period (in this case 2009).
} 
Looking at the dynamics of the current Default Rate over years we can notice an increase of default rate in 2009 corresponding to the deep recession following the global financial crisis in which it reaches its maximum value (DR_MAX).

Table 3 reports the scaling factor obtained using as long run default rate: the average DR (SF_mean) and the maximum_DR corresponding to a Bottom hypothesis (SF_max). In order to ensure consistency of scaling factors we calculated them from the static pool used to estimate the model, namely the true portfolio default.

\section{Table 3 Scaling factors based on the Ratios between DR_mean (or DR_MAX) and current DR.}

\begin{tabular}{ccc}
\hline DATA & SF_MEAN & SF_MAX \\
\hline & $(2)$ & $(3)$ \\
2006 & 1.000 & 1.267 \\
2007 & 1.322 & 1.674 \\
2008 & 1.318 & 1.669 \\
2009 & 0.791 & 1.000 \\
2010 & 0.887 & 1.123 \\
2011 & 0.974 & 1.233 \\
2012 & 0.937 & 1.187 \\
\hline
\end{tabular}

A preliminary evaluation of the application of scaling factors to the PD microdata can be obtained comparing the distribution of firms among risk buckets before and after their application with respect to a given year. In fact, even if the total number of defaulted obligors by year considering both TTC and PIT approaches doesn’t change, the default rate obligors' distribution among rating grades (risk buckets) will change.

In order to evaluate the effects of scaling factors application on the obligors' migration among risk buckets tables 4,5,6,7,8,9,10 the appendix report the backtesting for the years 20062012. Each table compares the results coming from a PiT PDs, a TtC PDs obtained applying the scaling factor based on the average default rate (SF_MEAN), and a TtC PD obtained applying a scaling factor based on the maximum default rate of the period (SF_MAX).

The mapping is achieved assigning the individual PDs to each risk class according to a fixed grading scale used within ECAF system. This scale is given by the following probability intervals: $(0 ; 0.03)(0.03 ; 0.1)(0.1 ; 0.4)$. An average PD given by the ratio between the number of defaulted firms and the number of firms in this class is then assigned to the obligors into the same grading class. 
Looking at the results concerning the PiT PDs in the sample 2006-2012 we can see that the average default probability for each rating bucket increases during recessions and decreases over expansions showing a pro-cyclical effect of the PiT rating system. In particular the number of obligors falling into the highest risk bucket (0.1- 0.4) rises from 103 in 2008 to 585 in 2009 (year corresponding to the maximum peak of the crisis).

Looking at the smoothing corrections, results concerning 2009 (year of maximum negative GDP growth) show as expected a migration of the number of obligors in the lowest risk classes when a TtC PDs scaling factor (SF_mean) is considered. The results concerning 2010, 2011 and 2012 obtained applying a scaling factor mean (SF_MEAN) greater than 1 also go in the expected direction. The number of firms in the lowest buckets significantly reduces producing TtC PDs.

As expected the scaling factor corresponding to the bottom hypothesis (SF_MAX) determines a shifting of obligors in the worst risk categories greater than this obtained with the average scaling factor in all the years considered. Comparing the backtesting results for the years 2006, 2007, 2008 and 2010, 2011, 2012 we can notice a decrease of the number of obligors’ defaults in the first risk bucket when shifting from PiT to TtC ratings with a bottom hypothesis of scaling factor (SF_MAX).

To give a more immediate view of the PD rescaling effects, graphs 2 and 3 display the variation of PiT PD, TTC PDs over the years together with GDP growth in the first and second risk buckets respectively.

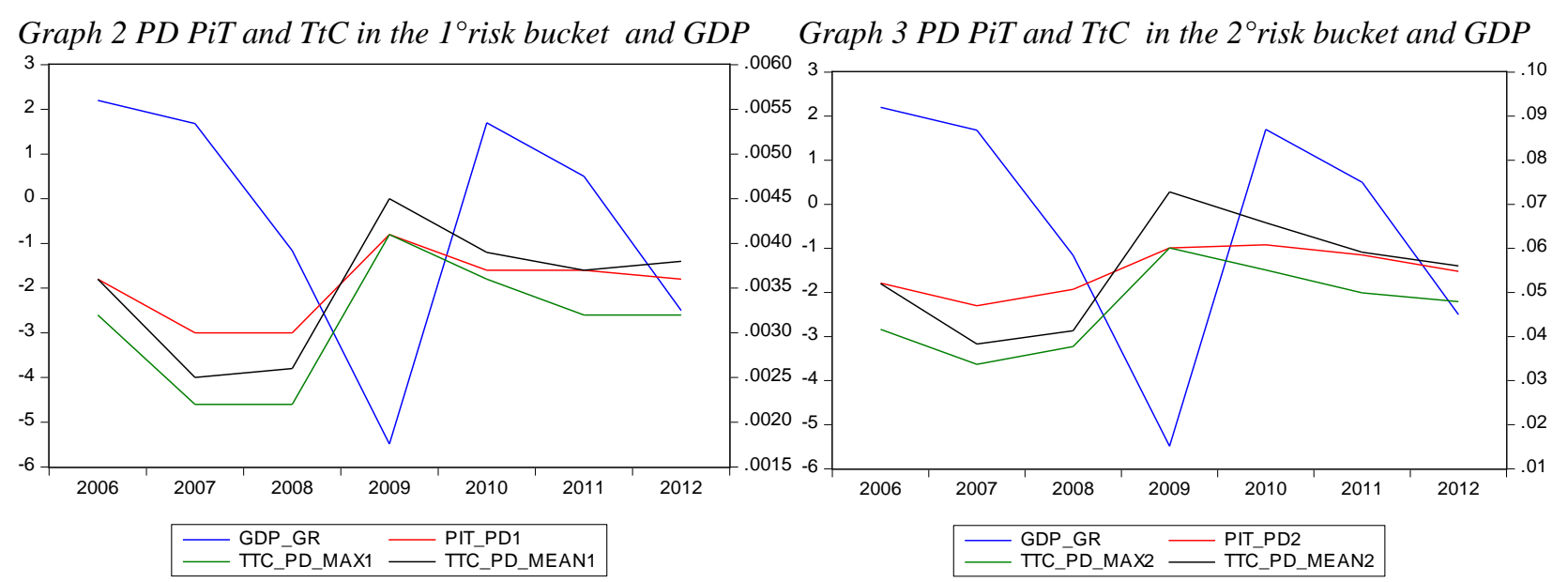

Overall, the results show a significant sensitivity of obligors' migrations among risk buckets over time. The findings also indicate that the use of TtC PDs free from business cycle movements (so called stressed scenario) produces a significant smoothing in terms of firms allocations among risk classes over time and contributes to reduce business cycle effects on obligors’ ratings. 
Looking at the graph in 2009 we find an increase of the average PD obtained using the SF_mean. in both risk buckets However looking at the number of defaulted firms we can see (table 7) that the obligors in the first and second risk buckets increase from 972 to 1097 and from 891 to 1068 showing an improvement in the obligors classification with respect to the PiT mapping.

This is important because a PD smoothing contributes to reduce the overall pro-cyclicality into the rating system , the credit cycle and in the last analysis it can enhance the financial system stability.

Graph 4 PD PiT and TtC in the $3^{\circ}$ risk bucket and GDP

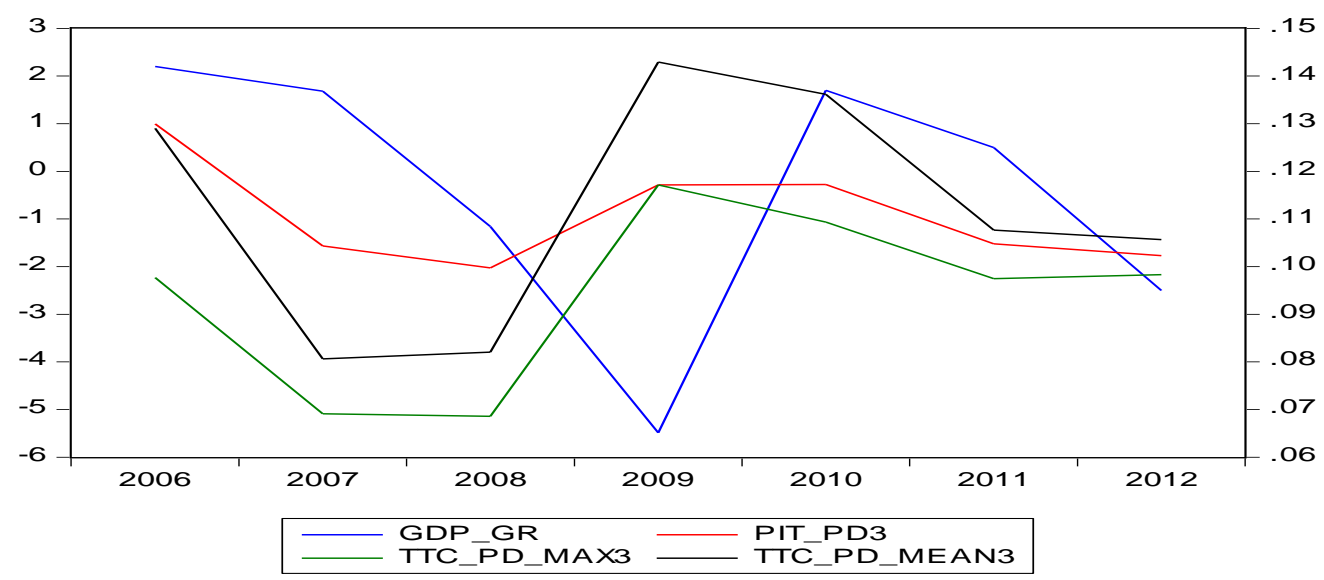

\subsection{Effects of rating scale definition on the rating stability}

The rating scale granularity ${ }^{19}$ plays a very important role in gaining rating accuracy and stability $^{20}$. A rating scale too granular would produce a good obligors' classification but would produce a very high variability of obligors' classifications over time reducing rating system stability.

To assess the effect of the rating scale adoption on rating stability I consider two different grades scales definitions. The first one is based on fixed thresholds external to the model (0.0 $0.03)(0.03-0.1)$ and $(0.1-0.4)$, the second one is based on a cluster $\mathrm{k}$ means algorithm that considers an Euclidean distance criterion among observations. The latter algorithm is a nonhierarchical method that groups all the obligors PDs into a predetermined number of clusters on the basis of their similarity with respect to a given measure (i.e. distance, correlation). The observations into the same cluster, being more similar, are expected to have a minimum "within" variance. Concerning the choice of distance criterion among observations I have found two approaches using

\footnotetext{
${ }^{19}$ The granularity refers to the number of risk classes considered into a grading scale.

${ }^{20}$ see Foglia et al, 2001 for a comparison of grading scales definition effects on IRB systems.
} 
cluster techniques for robust risk buckets detection: Foglia et al (2001) and Valles (2006). The first paper uses an Euclidean distance criterion among observations. The second paper uses a distance criterion based on a chi square minimization. ${ }^{21}$

It is important to notice that the cluster k means algorithm, being based on obligors PDs information over the whole sample 2006-2012, should produce to a certain extent thresholds buckets robust to obligors fluctuations.

After setting a number of clusters equal to three ${ }^{22}$, I carried out the $\mathrm{k}$ means algorithm on the estimated PDs. The grading scale defined by the cluster algorithm identifies the following risk buckets thresholds: (0 - 0.0213) (0.0213 -0.0741) (0.0741 -0.257).

The mapping algorithm described in (2) and (3) was then applied in order to determine the obligors distribution among the new risk buckets. Tables 11-17 in the appendix report the distribution of the obligors PiT PDs into the new risk buckets selected with the cluster analysis.

To analyze the effects of "robust" buckets detection in terms of stability graphs 5 and 6 compare the distribution of PiT default rates in the first and second risk buckets based on fixed thresholds with PiT PD distribution into endogenous risk buckets obtained with the cluster analysis.

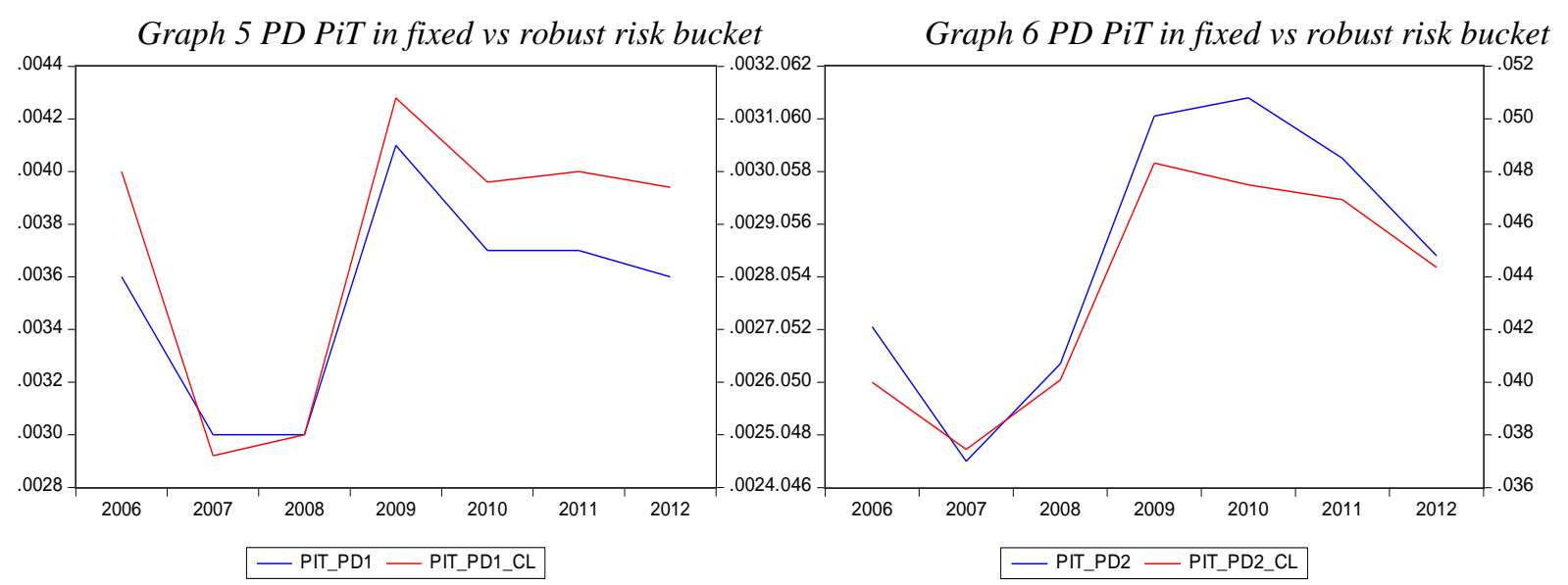

The results show that the application of the previous scaling factors to this more granular grading scale $^{23}$ produces also in this case a significant smoothing on obligor migrations among risk buckets. Looking at the graphs we can see that the distribution of obligors over time both in the first and second buckets displays a lower variability in case of PDs mapped into robust risk buckets.

\footnotetext{
${ }^{21}$ Since I don't have any a priori on the distance criterion in the paper I choose the distance Euclidean distance among observations because it is simple and intuitive. However this aspect doesn't represent the focus of the paper.

${ }^{22}$ The number of clusters has been chosen in order to compare the results with the number of fixed rating grades.

${ }^{23}$ The overall interval length considered in the cluster rating scale spans from $(0-0.257)$ against $(0-0.4)$.
} 
A further possibility to manage procyclicality into a rating system is to consider an "hybrid TtC system" that acts both on PD smoothing and on risk buckets length (see table 11-17 column 4-9). To assess the impact on rating stability of this last TtC rating approach Graph 6 and 7 show the effects of the application of the original scaling factors to the PiT PDs mapped into the "robust risk buckets” obtained through cluster analysis.

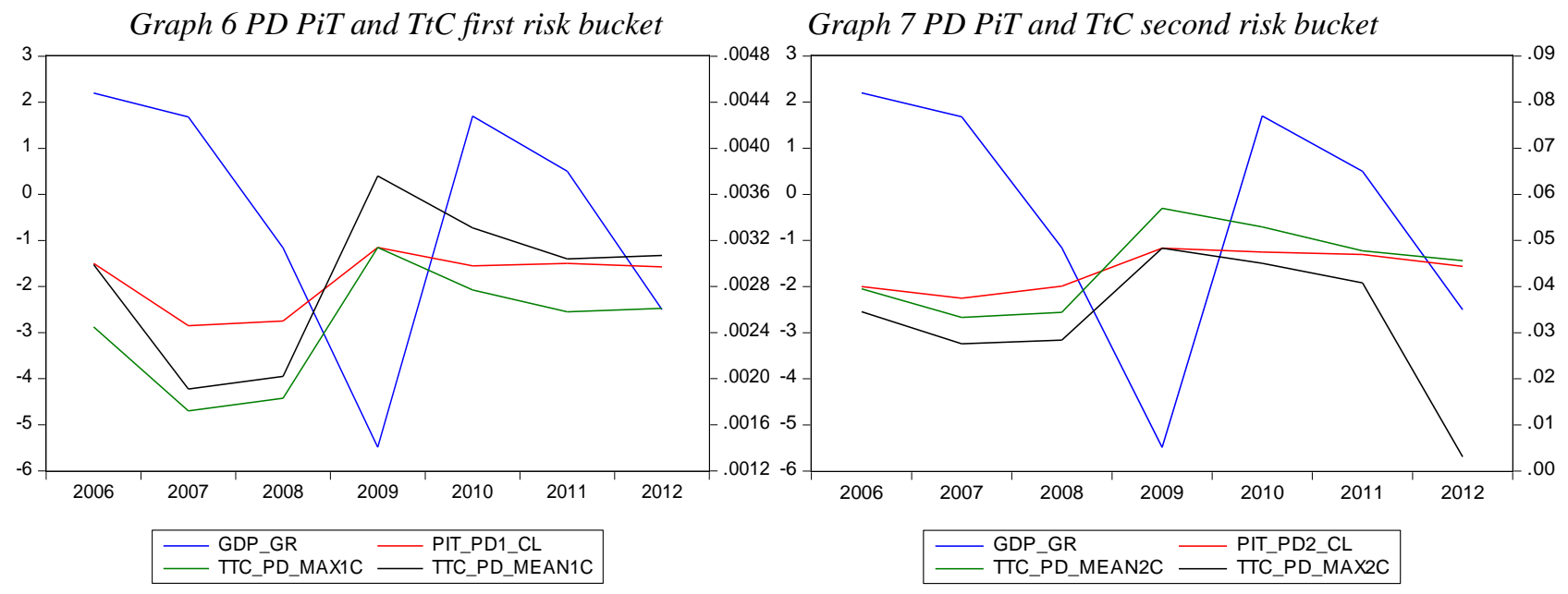

The results show that even in this case the smoothing produces an improvement of the obligors classifications into the lowest buckets that is even stronger compared fixed rating scales. In 2009 the number of firms classified into the first risk bucket shift from 725 to 886 .

To give a more straightforward description of a rating system stability over the cycle, table 18 in the appendix reports the percentage variation of the initial coorte of obligors from a PiT rating into the three risk buckets before and after the application of scaling factors for both fixed and endogenous risk buckets. The results show that the number of obligors that migrates in the highest risk class strongly decrease during the 2009 recession when using a scaling factor mean. The result holds considering both fixed and endogenous risk buckets. The results also indicate that the smoothing produces a more equal distribution of firms among risk grades when endogenous risk buckets are considered.

Overall, the results indicate that both an ex post PD smoothing and a robust risk buckets detection can reduce the procyclicality of ratings and thus improve their stability over time. Both the 
techniques analyzed represent a useful tool for central bankers dealing with collateral eligibility issues and macro-prudential regulation as well as private banks risk managers.

Both methods used to reduce procyclicality into the rating systems display advantages and shortcomings. For example the PD smoothing let the PDs to be less procyclical but at the same time can reduce the predictive power of the model. Analogously, the use of endogenous risk buckets would allow to obtain a more suitable obligors classification of a given portfolio but doesn't allow comparisons with the obligors PD distribution with that one of another financial institution because the mapping would be based on a different rating scale The sensitivity of obligors migration into the transition matrix to the smoothing parameters (i.e. scaling factors and risk buckets length) also bring to do considerations on the optimal choice of smoothing degree and scale granularity. In practice the level of PD smoothing and rating granularity should be chosen following criterions based on a desired level of the eligible collateral or on a desired target of risk.

\section{Conclusions}

A PiT rating system used to evaluate obligors' default probability contains several mechanisms potentially able to exacerbate the financial system pro-cyclicality. After analyzing the main shortcomings of a PiT rating system, I discuss possible improvements lines. Among the various solutions, I explore both the effects of ex post corrections of PiT PDs on the obligors allocations among risk buckets and the adoption of different rating scales definition.

The empirical results show that a PiT system without any mechanism of procyclicality correction produces an obligor allocation among risk buckets that is at least to a certain extent affected by business cycle.

The findings also show that, an ex post correction of PiT probability default based on countercyclical scaling factors taking into account of firms defaults long run dynamics allows to obtain a PD at firm level more in line with a $\mathrm{TtC}$ rating perspective. Since from a theoretical point of view the validation of a rating system should operate on PiT PDs (the predicted default rates are PiT), the use of an ex post smoothing of the estimated PDs represents a way to make operational a TtC mechanism without losing the possibility to operate the usual diagnostics on a PiT model.

The impact of an ex post correction obtained using scaling factors and evaluated in terms of firms migrations among risk buckets, indicates that the number of firms that migrates in the lowest classes is lower during expansions and higher during recessions. Overall, the results show that the ex post 
smoothing can reduce the stability problems linked to PiT rating systems. However, given the different degree of firms variability experimenting a migration among risk buckets after the scaling factor correction, the choice of the optimal smoothing is still open.

To assess the effects of rating scale adoption on rating stability I also considered two different grades scales definitions. The first one is based on fixed thresholds external to the model, the second one detects the rating buckets thresholds through a cluster analysis. With this second approach the rating buckets thresholds are detected "endogenously" to the model using cluster techniques.

Overall, the results show that a pro-cyclical rating policy can be mitigated using both an ex post smoothing and robust risk buckets thresholds. These findings have important implications both for Banking supervision purposes (amount of eligible collateral available in the banking sector, prudential regulation, deposits management) and for the financial system stability. 


\section{References}

Allen, L and A Saunders (2002): A survey of cyclical effects in credit risk measurement models, mimeo, New York University.

Bangia A. Diebold F.X Schuermann T. (2002) Rating migrations and business cycle, with applications to Credit Portfolio stress testing Journal of Banking and Finance, 26, 445- 474.

BIS (2004) Basel Committee on banking supervision International convergence on capital measurement and capital standards: a revised framework (Basel II).

BIS (2008) FSF Working Group on Market and Institutional Resilience Addressing financial system procyclicality: a possible framework.

Cesaroni T. Maccini L and M. Malgarini (2011) Business cycle stylized facts and inventory behaviour: new evidence for Euro Area International journal of production economics Vol. 133 n. 1 pag-12-24.

European Commission (2004) Accounting standards: Commission endorses IAS 39". Retrieved 2008-10-12.

Damato J. and Furfine (2003) Are credit rating procyclical? BIS WP n. 129.

Foglia A., S. Iannotti and P. Marullo Reedtz The Definition of the Grading Scales in Banks' Internal Rating Systems Economic Notes, 2001, vol. 30, issue 3, pages 421-456.

Financial Services Authority (2009): “A Regulatory Response to the Global Banking Crisis” Discussion Paper 09/02.

Ingolfsson S. and B. T. Elvarsson A guide to IMF stress testing: methods and models, Cyclical adjustment of point-in-time PD The Journal of the Operational Research Society Vol. 61, No. 3.

Kasyap A (2005) Financial system procyclicality Mimeo.

Kiff J. M.Kisser and L. Schumacher, 2013. "Rating Through-the-Cycle; What does the Concept Imply for Rating Stability and Accuracy?," IMF Working Papers 13/64,

Loffler Gunter (2004) An anatomy of rating through the cycle Journal of Banking and Finance 28 pag. 695-720.

Lowe P. (2002) Credit risk measurement and procyclicality BIS WP N. 116.

Nickell P. Perraudin W. and Varotto S. (2001) Stability of rating transitions Bank of England wp133.

Valles V. (2006) Stability of a "through the cycle" rating system during a financial crisis Financial stability institute BIS. 


\section{Appendix}

Proposition 1 Assume a fixed rating space $S=\left(R_{1}, R_{2}, \ldots . R_{k-h}, \ldots, R_{k-1}, R_{k}\right)$ with probability intervals $(j ; j+m)$ defining each risk bucket $R_{k-h}$, then the probability of migration from bucket $R_{k-h}$ to bucket $R_{k-l}$ of obligor $j$ in switching from an expansion (recession) to a recession (expansion) will be higher (lower) for PiT PD than for TtC PD.

The intuition for the above result follows from the fact that at firm level PIT PD displays an higher variability over time w.r.t. a smoothed TTC PD by definition. This fact, under a recession determines an increase of PD over time greater than under a TTC rating. This would produce a greater firms migrations in the highest buckets (worst obligors) over recessions and to the lowest buckets (best obligors) during expansions because it will be more common to have an estimated PD in $\mathrm{t}$ that overpass the risk bucket from $\mathrm{t}$ (i.e expansion) to $\mathrm{t}+1$ (i.e. recession).

\section{CASE OF RECESSION in $\mathrm{t}+1$}

\section{Proof:}

Without loss of generality assume a mapping algorithm that considers a rating space $\mathrm{S}$ with only two risk buckets $R 1(0, j)$ and $R 2(j, 1)$ with $0<j<1$. Assume a PIT rating system. The corresponding transition matrix of the obligors from $\mathrm{t}$ to $\mathrm{t}+1$ will be:

\section{Transition matrix under a PIT system}

\begin{tabular}{|l|l|l|l|}
\hline & \multicolumn{2}{|c|}{$\mathrm{t}+1$} & \\
\hline $\mathrm{t}$ & \multicolumn{1}{|c|}{$\mathrm{R} 1(0, \mathrm{j})$} & \multicolumn{1}{|c|}{$\mathrm{R} 1(\mathrm{j}, 1)$} & \\
\hline R1 $(0, \mathrm{j})$ & $N_{1}^{1}$ & $N_{1}^{2}$ & $N 1(t)$ \\
\hline R2 (j,1) & $N_{2}^{1}$ & $N_{2}^{2}$ & $N 2(t)$ \\
\hline & $N 1(t+1)$ & $N 2(t+1)$ & $N(t)=N(t+1)$ \\
\hline
\end{tabular}

Let the frequency of migration form bucket R1 to R2 under a PIT rating system be:

$$
f_{i}^{P I T}(t)=N_{1}^{2} / N_{1}(t)
$$

where $f_{i}^{P I T}(t)$ is the marginal transition frequency from rating 1 to rating 2 in 1 period. $N_{1}^{2}$ is the number of firms that move from R1 to R2 and $N_{1}(t)$ is the total number of obligors belonging to rating $\mathrm{R} 1$ at the beginnings of the period. 
Now assume a TTC rating system with the same mapping algorithm $M$ and the same rating space $S$. The corresponding transition matrix of the obligors from $\mathrm{t}$ to $\mathrm{t}+1$ will be:

Transition matrix under a TTC system

\begin{tabular}{|l|l|l|l|}
\hline & \multicolumn{2}{|c|}{$\mathrm{t}+1$} & \\
\hline $\mathrm{t}$ & \multicolumn{1}{|c|}{$\mathrm{R} 1(0, \mathrm{j})$} & \multicolumn{1}{|c|}{$\mathrm{R}(\mathrm{j}, 1)$} & \\
\hline $\mathrm{R} 1(0, \mathrm{j})$ & $N *_{1}^{1}$ & $N^{2}$ & $N^{*} 1(t)$ \\
\hline $\mathrm{R} 2(\mathrm{j}, 1)$ & $N^{* 1}$ & $N^{* 2}$ & $N^{*} 2(t)$ \\
\hline & $N^{*} 1(t+1)$ & $N^{*} 2(t+1)$ & $N^{*}(t)=N(t+1)$ \\
\hline
\end{tabular}

Let the frequency of migration form bucket 1 to 2 under a TTC rating system be:

$f_{i}^{T T C}(t)=N *_{1}^{2} / N *_{1}(t)$

Since $P D(t) P I T>P D(t) T T C$, the number of firms assigned to $\mathrm{R} 1(0, \mathrm{j})$ under PIT will be $<=$ to those under PIT. Thus $N 1(t)=>N * 1(t)$. Since by definition of frequency $N{ }^{* 2}<=N{ }_{1}^{*}(t)$.

Under recession follows that $f_{i}^{P I T}(t)>=f_{i}^{T T C}(t)$ 
Proposition 2 Assume a fixed rating space $S=\left(R_{1}, R_{2}, \ldots . R_{k-h}, \ldots, R_{k-1}, R_{k}\right)$ with probability intervals $(j ; j+m)$; assume a more granular rating space $S^{*}=\left(R_{1}, R_{2}, \ldots . R_{k^{*}-h}, \ldots, R_{k^{*}-1}, R_{k^{*}}\right)$ with $R k^{*}>R k$, and $\left(k^{*}-h\right)<(k-h)$ for each $R$, the Probability of migration from bucket $k^{*}-h$ to bucket $k^{*}-l$ of obligor $j$ over time will be higher under $S^{*}$ compared to $S$ for both PiT and TtC PD rating philosophies.

Intuitively, the above result reflects the fact that shorter risk buckets will display lower probability thresholds and thus the frequency of overpassing such bucket PD from $\mathrm{t}$ to $\mathrm{t}+1$ will be higher under $S^{*}$.

\section{CASE OF RECESSION $(P D(t+1)>P D(t))$}

Proof: In case of a S rating space the scale the mapping algorithm will be:

- PIT case:

$$
\begin{gathered}
f_{K-H}\left(P D_{i}\right)_{i}^{P I T}(t)=1 \quad \text { if }\left(k-h<P D_{i}^{P I T}(t)=<k-l\right) \text { and } 0 \text { otherwise. Under } S^{*} \text { we will have: } \\
f_{K-H}\left(P D_{i}\right)_{i}^{P I T}(t)=1 \quad \text { if }\left(k^{*}-h<P D_{i}^{P I T}(t)=<k^{*}-l\right)
\end{gathered}
$$

Since $\left(k^{*}-l\right)<(k-l)$ the $\mathrm{PD}_{\mathrm{S}^{*}}(\mathrm{t})$ of obligor i under $\mathrm{S}^{*}$ will be $<=$ to $\mathrm{PD}_{\mathrm{S}}(\mathrm{t})$ of obligor i under $\mathrm{S}$

- TTC case:

$$
f_{K-H}\left(P D_{i}\right)_{i}^{T T C}(t)=1 \text { if }\left(k^{*}-h<P D_{i}^{P I T}(t) * S F(t)=<k^{*}-l\right)
$$

The condition for moving from bucket $k^{*}$-h to bucket $k^{*}-l$ will be $S F(t)<\frac{k^{*}-h}{P D^{P I T}(t)}$ Since the probability interval $\left(k^{*}-l\right)<(k-l)$ by definition, we will have $S F^{*}(t)<S F(t)$. 


\section{Appendix}

\section{Fixed rating buckets}

Table 4 Backtesting year 2006

\begin{tabular}{|c|c|c|c|c|c|c|c|c|c|}
\hline 2006 & \multicolumn{3}{|c|}{ PiT PD } & \multicolumn{3}{|c|}{ SF_mean_PD_correction } & \multicolumn{3}{|c|}{ SF_Max_PD correction } \\
\hline $\begin{array}{c}\text { Range of } \\
\text { PD }\end{array}$ & Companies & Default & DR & Companies & Default & DR & Companies & Default & DR \\
\hline column & -1 & -2 & -3 & -4 & -5 & -6 & -7 & -8 & -9 \\
\hline $0.0-0.03$ & 191457 & 697 & 0.0036 & 191453 & 697 & 0.0036 & 188478 & 604 & 0.0032 \\
\hline 0.03- 0.1 & 12612 & 657 & 0.0521 & 12590 & 655 & 0.0520 & 12966 & 540 & 0.0416 \\
\hline $0.1-0.4$ & 1439 & 187 & 0.1300 & 1465 & 189 & 0.1290 & 4064 & 397 & 0.0977 \\
\hline$>0.4$ & & & & & & & & & \\
\hline Total & 205508 & 1541 & 0.0075 & 205508 & 1541 & 0.0075 & 205508 & 1541 & 0.0075 \\
\hline
\end{tabular}

Table 5 Backtesting year 2007

\begin{tabular}{|l|r|r|r|r|r|r|r|r|r|}
\hline \multicolumn{1}{|c|}{ 2007 } & \multicolumn{3}{|c|}{ PiT PD } & \multicolumn{2}{c|}{ SF_mean_PD_correction } & \multicolumn{2}{c|}{ SF_Max_PD correction } \\
\hline $\begin{array}{l}\text { Range } \\
\text { of PD }\end{array}$ & Companies & Default & \multicolumn{1}{l}{ DR } & Companies & Default & DR & Companies & Default & DR \\
\hline column & $\mathbf{- 1}$ & $\mathbf{- 2}$ & $\mathbf{- 3}$ & $\mathbf{- 4}$ & $\mathbf{- 5}$ & $\mathbf{- 6}$ & $\mathbf{- 7}$ & $\mathbf{- 8}$ & $\mathbf{- 9}$ \\
\hline $0.0-0.03$ & 210842 & 625 & 0.0030 & 207689 & 523 & 0.0025 & 204322 & 442 & 0.0022 \\
\hline $0.03-0.1$ & 11511 & 541 & 0.0470 & 12196 & 467 & 0.0383 & 13789 & 465 & 0.0337 \\
\hline $0.1-0.4$ & 968 & 101 & 0.1043 & 3436 & 277 & 0.0806 & 5210 & 360 & 0.0691 \\
\hline$>0.4$ & & & & & & & & & \\
\hline Total & $\mathbf{2 2 3 3 2 1}$ & $\mathbf{1 2 6 7}$ & $\mathbf{0 . 0 0 5 7}$ & $\mathbf{2 2 3 3 2 1}$ & $\mathbf{1 2 6 7}$ & $\mathbf{0 . 0 0 5 7}$ & $\mathbf{2 2 3 3 2 1}$ & $\mathbf{1 2 6 7}$ & $\mathbf{0 . 0 0 5 7}$ \\
\hline
\end{tabular}

Table 6 Backtesting year 2008

\begin{tabular}{|l|r|r|r|r|r|r|r|r|r|}
\hline \multicolumn{1}{|c|}{ 2008 } & \multicolumn{3}{|c|}{ PiT PD } & \multicolumn{2}{c|}{ SF_mean_PD_correction } & \multicolumn{3}{c|}{ SF_Max_PD correction } \\
\hline $\begin{array}{l}\text { Range of } \\
\text { PD }\end{array}$ & Companies & Default & \multicolumn{1}{l}{ DR } & Companies & Default & \multicolumn{1}{l|}{ DR } & Companies & Default & DR \\
\hline column & $\mathbf{- 1}$ & $\mathbf{- 2}$ & $\mathbf{- 3}$ & $\mathbf{- 4}$ & $\mathbf{- 5}$ & $\mathbf{- 6}$ & $\mathbf{- 7}$ & $\mathbf{- 8}$ & $\mathbf{- 9}$ \\
\hline $0.0-0.03$ & 230871 & 699 & 0.0030 & 227536 & 583 & 0.0026 & 223722 & 484 & 0.0022 \\
\hline $0.03-0.1$ & 11497 & 583 & 0.0507 & 12269 & 507 & 0.0413 & 14516 & 547 & 0.0377 \\
\hline $0.1-0.4$ & 1033 & 103 & 0.0997 & 3596 & 295 & 0.0820 & 5163 & 354 & 0.0686 \\
\hline$>0.4$ & & & & & & & & & \\
\hline Total & $\mathbf{2 4 3 4 0 1}$ & $\mathbf{1 3 8 5}$ & $\mathbf{0 . 0 0 5 7}$ & $\mathbf{2 4 3 4 0 1}$ & $\mathbf{1 3 8 5}$ & $\mathbf{0 . 0 0 5 7}$ & $\mathbf{2 4 3 4 0 1}$ & $\mathbf{1 3 8 5}$ & $\mathbf{0 . 0 0 5 7}$ \\
\hline
\end{tabular}

Table 7 Backtesting year 2009

\begin{tabular}{|l|c|c|l|c|c|l|l|l|l|}
\hline \multicolumn{3}{|c|}{ P009 } & \multicolumn{3}{|c|}{ PiT PD } & \multicolumn{3}{c|}{ SF_mean_PD_correction } & \multicolumn{3}{c|}{ SF_Max_PD correction } \\
\hline $\begin{array}{l}\text { Range of } \\
\text { PD }\end{array}$ & Companies & Default & DR & Companies & Default & DR & Companies & Default & DR \\
\hline column & -1 & -2 & -3 & -4 & -5 & -6 & -7 & $-\mathbf{8}$ & $\mathbf{- 9}$ \\
\hline
\end{tabular}




\begin{tabular}{|l|r|r|r|r|r|r|r|r|r|}
$0.0-0.03$ & 238135 & 972 & 0.0041 & 241316 & 1097 & 0.0045 & 238135 & 972 & 0.0041 \\
\hline $0.03-0.1$ & 14828 & 891 & 0.0601 & 14662 & 1068 & 0.0728 & 14828 & 891 & 0.0601 \\
\hline $0.1-0.4$ & 4995 & 585 & 0.1171 & 1980 & 283 & 0.1429 & 4995 & 585 & 0.1171 \\
\hline$>0.4$ & & & & & & & & & \\
\hline Total & $\mathbf{2 5 7 9 6 1}$ & $\mathbf{2 4 4 8}$ & $\mathbf{0 . 0 0 9 5}$ & $\mathbf{2 5 7 9 6 1}$ & $\mathbf{2 4 4 8}$ & $\mathbf{0 . 0 0 9 5}$ & $\mathbf{2 5 7 9 6 1}$ & $\mathbf{2 4 4 8}$ & $\mathbf{0 . 0 0 9 5}$ \\
\hline
\end{tabular}

Table 8 Backtesting year 2010

\begin{tabular}{|l|r|r|r|r|r|r|r|r|r|}
\hline $\mathbf{2 0 1 0}$ & \multicolumn{4}{l|}{ PiT PD } & \multicolumn{3}{l|}{ SF_mean_PD_correction } & \multicolumn{3}{l|}{ SF_Max_PD correction } \\
\hline $\begin{array}{l}\text { Range of } \\
\text { PD }\end{array}$ & Companies & Default & \multicolumn{1}{l}{ DR } & Companies & Default & \multicolumn{1}{l|}{ DR } & Companies & Default & DR \\
\hline column & $\mathbf{- 1}$ & $\mathbf{- 2}$ & $\mathbf{- 3}$ & $\mathbf{- 4}$ & $\mathbf{- 5}$ & $\mathbf{- 6}$ & $\mathbf{- 7}$ & $\mathbf{- 8}$ & $\mathbf{- 9}$ \\
\hline $0.0-0.03$ & 247836 & 924 & 0.0037 & 249346 & 969 & 0.0039 & 245959 & 875 & 0.0036 \\
\hline $0.03-0.1$ & 14612 & 888 & 0.0608 & 14371 & 945 & 0.0658 & 15414 & 849 & 0.0551 \\
\hline $0.1-0.4$ & 3744 & 439 & 0.1173 & 2475 & 337 & 0.1362 & 4819 & 527 & 0.1094 \\
\hline$>0.4$ & & & & & & & & & \\
\hline Total & $\mathbf{2 6 6 1 9 3}$ & $\mathbf{2 2 5 1}$ & $\mathbf{0 . 0 0 8 5}$ & $\mathbf{2 6 6 1 9 3}$ & $\mathbf{2 2 5 1}$ & $\mathbf{0 . 0 0 8 5}$ & $\mathbf{2 6 6 1 9 3}$ & $\mathbf{2 2 5 1}$ & $\mathbf{0 . 0 0 8 5}$ \\
\hline
\end{tabular}

Table 9 Backtesting year 2011

\begin{tabular}{|l|r|r|r|r|r|r|r|r|r|}
\hline \multicolumn{1}{|c|}{ 2011 } & \multicolumn{3}{|c|}{ PiT PD } & \multicolumn{2}{c|}{ SF_mean_PD_correction } & \multicolumn{2}{c|}{ SF_Max_PD correction } \\
\hline $\begin{array}{l}\text { Range of } \\
\text { PD }\end{array}$ & Companies & Default & \multicolumn{1}{l}{ DR } & Companies & Default & \multicolumn{1}{l|}{ DR } & Companies & Default & DR \\
\hline column & $\mathbf{- 1}$ & $-\mathbf{2}$ & $\mathbf{- 3}$ & $\mathbf{- 4}$ & $\mathbf{- 5}$ & $\mathbf{- 6}$ & $\mathbf{- 7}$ & $\mathbf{- 8}$ & $\mathbf{- 9}$ \\
\hline $0.0-0.03$ & 253736 & 929 & 0.0037 & 254093 & 944 & 0.0037 & 250156 & 806 & 0.0032 \\
\hline $0.03-0.1$ & 12385 & 725 & 0.0585 & 12276 & 725 & 0.0591 & 14264 & 712 & 0.0499 \\
\hline $0.1-0.4$ & 4075 & 427 & 0.1048 & 3827 & 412 & 0.1077 & 5776 & 563 & 0.0975 \\
\hline$>0.4$ & & & & & & & & & \\
\hline Total & $\mathbf{2 7 0 2 0 1}$ & $\mathbf{2 0 8 1}$ & $\mathbf{0 . 0 0 7 7}$ & $\mathbf{2 7 0 2 0 1}$ & $\mathbf{2 0 8 1}$ & $\mathbf{0 . 0 0 7 7}$ & $\mathbf{2 7 0 2 0 1}$ & $\mathbf{2 0 8 1}$ & $\mathbf{0 . 0 0 7 7}$ \\
\hline
\end{tabular}

Table 10 Backtesting year 2012

\begin{tabular}{|l|r|r|r|r|r|r|r|r|r|}
\hline \multicolumn{1}{|c|}{ 2012 } & \multicolumn{3}{|c|}{ PiT PD } & \multicolumn{2}{c|}{ SF_mean_PD_correction } & \multicolumn{3}{c|}{ SF_Max_PD correction } \\
\hline $\begin{array}{l}\text { Range of } \\
\text { PD }\end{array}$ & Companies & Default & \multicolumn{1}{l}{ DR } & Companies & Default & \multicolumn{1}{l|}{ DR } & Companies & Default & DR \\
\hline column & $\mathbf{- 1}$ & $\mathbf{- 2}$ & $\mathbf{- 3}$ & $\mathbf{- 4}$ & $\mathbf{- 5}$ & $\mathbf{- 6}$ & $\mathbf{- 7}$ & $\mathbf{- 8}$ & $\mathbf{- 9}$ \\
\hline $0.0-0.03$ & 249799 & 909 & 0.0036 & 250916 & 956 & 0.0038 & 246423 & 790 & 0.0032 \\
\hline $0.03-0.1$ & 13678 & 749 & 0.0548 & 12935 & 725 & 0.0560 & 15663 & 750 & 0.0479 \\
\hline $0.1-0.4$ & 4781 & 489 & 0.1023 & 4410 & 466 & 0.1057 & 6175 & 607 & 0.0983 \\
\hline$>0.4$ & & & & & & & & & \\
\hline Total & $\mathbf{2 6 8 2 6 3}$ & $\mathbf{2 1 4 7}$ & $\mathbf{0 . 0 0 8}$ & $\mathbf{2 6 8 2 6 3}$ & $\mathbf{2 1 4 7}$ & $\mathbf{0 . 0 0 8}$ & $\mathbf{2 6 8 2 6 3}$ & $\mathbf{2 1 4 7}$ & $\mathbf{0 . 0 0 8}$ \\
\hline
\end{tabular}




\section{Cluster rating buckets aggregation (K means algorithm)}

Table 11 Backtesting year 2006

\begin{tabular}{|l|r|r|r|r|r|r|r|r|r|}
\hline \multicolumn{1}{|c|}{ 2006 } & \multicolumn{4}{|c|}{ PiT PD } & \multicolumn{2}{c|}{ SF_mean_PD_correction } & \multicolumn{2}{c|}{ SF_Max_PD correction } \\
\hline $\begin{array}{l}\text { Range of } \\
\text { PD }\end{array}$ & Companies & \multicolumn{1}{c|}{ Default } & \multicolumn{1}{l|}{ DR } & Companies & \multicolumn{1}{c|}{ Default } & \multicolumn{1}{c|}{ DR } & Companies & Default & DR \\
\hline column & $\mathbf{( 1 )}$ & $\mathbf{( 2 )}$ & $\mathbf{( 3 )}$ & $\mathbf{( 4 )}$ & $\mathbf{( 5 )}$ & $\mathbf{( 6 )}$ & $\mathbf{( 7 )}$ & $\mathbf{( 8 )}$ & $\mathbf{( 9 )}$ \\
\hline $\begin{array}{l}0.0- \\
0.0213\end{array}$ & 187133 & 559 & 0.003 & 187128 & 559 & 0.003 & 182909 & 448 & 0.002 \\
\hline $\begin{array}{l}0.0213- \\
0.0741\end{array}$ & 13572 & 537 & 0.040 & 13571 & 536 & 0.040 & 15953 & 551 & 0.035 \\
\hline $\begin{array}{l}0.074- \\
0.257\end{array}$ & 4803 & 445 & 0.093 & 4809 & 446 & 0.093 & 6646 & 542 & 0.003 \\
\hline$>0.257$ & & & & & & & & & \\
\hline Total & $\mathbf{2 0 5 5 0 8}$ & $\mathbf{1 5 4 1}$ & $\mathbf{0 . 0 0 7 5}$ & $\mathbf{2 0 5 5 0 8}$ & $\mathbf{1 5 4 1}$ & $\mathbf{0 . 0 0 7 5}$ & $\mathbf{2 0 5 5 0 8}$ & $\mathbf{1 5 4 1}$ & $\mathbf{0 . 0 0 7 5}$ \\
\hline
\end{tabular}

Table 12 Backtesting year 2007

\begin{tabular}{|c|c|c|c|c|c|c|c|c|c|}
\hline 2007 & \multicolumn{3}{|c|}{ PiT PD } & \multicolumn{3}{|c|}{ SF_mean_PD_correction } & \multicolumn{3}{|c|}{ SF_Max_PD correction } \\
\hline $\begin{array}{l}\text { Range } \\
\text { of PD }\end{array}$ & Companies & Default & DR & Companies & Default & DR & Companies & Default & DR \\
\hline column & (1) & (2) & (3) & (4) & (5) & (6) & (7) & (8) & (9) \\
\hline $\begin{array}{l}0.0- \\
0.0213\end{array}$ & 207048 & 509 & 0.002 & 202395 & 386 & 0.002 & 199171 & 342 & 0.002 \\
\hline $\begin{array}{l}0.0213- \\
0.0741\end{array}$ & 12605 & 472 & 0.037 & 15300 & 510 & 0.033 & 16393 & 452 & 0.028 \\
\hline $\begin{array}{l}0.0741- \\
0.257\end{array}$ & 3668 & 286 & 0.002 & 5626 & 371 & 0.066 & 7688 & 463 & 0.002 \\
\hline$>0.257$ & & & & & & & 69 & 10 & 0.145 \\
\hline Total & 223321 & 1267 & 0.0057 & 223321 & 1267 & 0.0057 & 223321 & 1267 & 0.0057 \\
\hline
\end{tabular}

Table 13 Backtesting year 2008

\begin{tabular}{|c|c|c|c|c|c|c|c|c|c|}
\hline \multirow{2}{*}{$\begin{array}{l}\mathbf{2 0 0 8} \\
\text { Range of } \\
\text { PD }\end{array}$} & \multicolumn{3}{|c|}{ PiT PD } & \multicolumn{3}{|c|}{ SF_mean_PD_correction } & \multicolumn{3}{|c|}{ SF_Max_PD correction } \\
\hline & Companies & Default & DR & Companies & Default & $\mathrm{DR}$ & Companies & Default & DR \\
\hline column & (1) & (2) & (3) & (4) & (5) & (6) & (7) & (8) & (9) \\
\hline $\begin{array}{l}0.0- \\
0.0213\end{array}$ & 226792 & 566 & 0.002 & 221698 & 448 & 0.002 & 218379 & 399 & 0.002 \\
\hline $\begin{array}{l}0.0213- \\
0.0741 \\
\end{array}$ & 12751 & 511 & 0.040 & 16066 & 553 & 0.034 & 17298 & 491 & 0.028 \\
\hline $\begin{array}{l}0.0741- \\
0.257 \\
\end{array}$ & 3858 & 308 & 0.080 & 5637 & 384 & 0.068 & 7634 & 487 & 0.064 \\
\hline$>0.257$ & & & & & & & 90 & 8 & 0.089 \\
\hline Total & 243401 & 1385 & 0.0057 & 243401 & 1385 & 0.0057 & 243401 & 1385 & 0.0057 \\
\hline
\end{tabular}


Table 14 Backtesting year 2009

\begin{tabular}{|c|c|c|c|c|c|c|c|c|c|}
\hline 2009 & \multicolumn{3}{|c|}{ PiT PD } & \multicolumn{3}{|c|}{ SF_mean_PD_correction } & \multicolumn{3}{|c|}{ SF_Max_PD correction } \\
\hline Range of PD & Companies & Default & DR & Companies & Default & DR & Companies & Default & DR \\
\hline column & (1) & (2) & (3) & (4) & (5) & (6) & (7) & (8) & (9) \\
\hline $\begin{array}{l}0.0- \\
0.0213\end{array}$ & 231192 & 725 & 0.003 & 235925 & 886 & 0.004 & 231191 & 725 & 0.003 \\
\hline $\begin{array}{l}0.0213- \\
0.0741\end{array}$ & 19040 & 920 & 0.048 & 16535 & 942 & 0.057 & 19041 & 920 & 0.048 \\
\hline $\begin{array}{l}0.0741- \\
0.257\end{array}$ & 7726 & 803 & 0.104 & 5498 & 620 & 0.113 & 7726 & 803 & 0.104 \\
\hline$>0.257$ & & & & & & & & & \\
\hline Total & 257961 & 2448 & 0.0095 & 257961 & 2448 & 0.0095 & 257961 & 2448 & 0.0095 \\
\hline
\end{tabular}

Table 15 Backtesting year 2010

\begin{tabular}{|l|r|r|l|r|r|r|r|r|r|}
\hline \multicolumn{1}{|c|}{$\mathbf{2 0 1 0}$} & \multicolumn{4}{|c|}{ PiT PD } & \multicolumn{3}{c|}{ SF_mean_PD_correction } & \multicolumn{3}{c|}{ SF_Max_PD correction } \\
\hline Range of PD & Companies & Default & \multicolumn{1}{l|}{ DR } & Companies & Default & DR & Companies & Default & DR \\
\hline column & $\mathbf{( 1 )}$ & $\mathbf{( 2 )}$ & $\mathbf{( 3 )}$ & $\mathbf{( 4 )}$ & $\mathbf{( 5 )}$ & $\mathbf{( 6 )}$ & $\mathbf{( 7 )}$ & $\mathbf{( 8 )}$ & $\mathbf{( 9 )}$ \\
\hline $\begin{array}{l}0.0- \\
0.0213\end{array}$ & 241698 & 720 & 0.003 & 244144 & 808 & 0.003 & 239721 & 664 & 0.003 \\
\hline $\begin{array}{l}0.0213- \\
0.0741\end{array}$ & 17731 & 842 & 0.047 & 16852 & 892 & 0.053 & 18717 & 843 & 0.045 \\
\hline $\begin{array}{l}0.0741- \\
0.257\end{array}$ & 6763 & 689 & 0.102 & 5196 & 551 & 0.106 & 7742 & 743 & 0.096 \\
\hline$>0.257$ & & & & & & & 12 & 1 & 0.083 \\
\hline Total & $\mathbf{2 6 6 1 9 3}$ & $\mathbf{2 2 5 1}$ & $\mathbf{0 . 0 0 8 5}$ & $\mathbf{2 6 6 1 9 3}$ & $\mathbf{2 2 5 1}$ & $\mathbf{0 . 0 0 8 5}$ & $\mathbf{2 6 6 1 9 3}$ & $\mathbf{2 2 5 1}$ & $\mathbf{0 . 0 0 8 5}$ \\
\hline
\end{tabular}

Table 16 Backtesting year 2011

\begin{tabular}{|l|c|c|c|c|c|c|c|c|c|}
\hline \multicolumn{1}{|c|}{2011} & \multicolumn{4}{|c|}{ PiT PD } & \multicolumn{3}{c|}{ SF_mean_PD_correction } & \multicolumn{3}{c|}{ SF_Max_PD correction } \\
\hline Range of PD & Companies & Default & \multicolumn{1}{l|}{ DR } & Companies & Default & DR & Companies & Default & DR \\
\hline column & $\mathbf{( 1 )}$ & $\mathbf{( 2 )}$ & $\mathbf{( 3 )}$ & $\mathbf{( 4 )}$ & $\mathbf{( 5 )}$ & $\mathbf{( 6 )}$ & $\mathbf{( 7 )}$ & $\mathbf{( 8 )}$ & $\mathbf{( 9 )}$ \\
\hline $\begin{array}{l}0.0- \\
0.0213\end{array}$ & 248201 & 744 & 0.003 & 248563 & 756 & 0.003 & 244438 & 631 & 0.003 \\
\hline $\begin{array}{l}0.0213- \\
0.0741\end{array}$ & 15512 & 728 & 0.047 & 15333 & 732 & 0.048 & 17532 & 715 & 0.041 \\
\hline $\begin{array}{l}0.0741- \\
0.257\end{array}$ & 6483 & 609 & 0.094 & 6300 & 593 & 0.094 & 8107 & 716 & 0.088 \\
\hline$>0.257$ & & & & & & & 119 & 19 & 0.160 \\
\hline Total & $\mathbf{2 7 0 2 0 1}$ & $\mathbf{2 0 8 1}$ & $\mathbf{0 . 0 0 7 7}$ & $\mathbf{2 7 0 2 0 1}$ & $\mathbf{2 0 8 1}$ & $\mathbf{0 . 0 0 7 7}$ & $\mathbf{2 7 0 2 0 1}$ & $\mathbf{2 0 8 1}$ & $\mathbf{0 . 0 0 7 7}$ \\
\hline
\end{tabular}


Table 17 Backtesting year 2012

\begin{tabular}{|l|c|c|c|c|c|c|c|r|r|}
\hline \multicolumn{1}{|c|}{$\mathbf{2 0 1 2}$} & \multicolumn{4}{|c|}{ PiT PD } & \multicolumn{3}{c|}{ SF_mean_PD_correction } & \multicolumn{3}{c|}{ SF_Max_PD correction } \\
\hline Range of PD & Companies & Default & DR & Companies & Default & DR & Companies & Default & DR \\
\hline column & $\mathbf{( 1 )}$ & $\mathbf{( 2 )}$ & $\mathbf{( 3 )}$ & $\mathbf{( 4 )}$ & $\mathbf{( 5 )}$ & $\mathbf{( 6 )}$ & $\mathbf{( 7 )}$ & $\mathbf{( 8 )}$ & $\mathbf{( 9 )}$ \\
\hline $0.0-0.0213$ & 244135 & 724 & 0.003 & 245059 & 752 & 0.003 & 240990 & 629 & 0.003 \\
\hline $\begin{array}{l}0.0213- \\
0.0741\end{array}$ & 16929 & 751 & 0.044 & 16470 & 751 & 0.046 & 18223 & 718 & 0.039 \\
\hline $\begin{array}{l}0.0741- \\
0.257\end{array}$ & 7197 & 672 & 0.003 & 6732 & 644 & 0.003 & 8893 & 778 & 0.003 \\
\hline$>0.257$ & & & & & & & 155 & 22 & 0.142 \\
\hline Total & $\mathbf{2 6 8 2 6 3}$ & $\mathbf{2 1 4 7}$ & $\mathbf{0 . 0 0 8 0}$ & $\mathbf{2 6 8 2 6 3}$ & $\mathbf{2 1 4 7}$ & $\mathbf{0 . 0 0 8}$ & $\mathbf{2 6 8 2 6 3}$ & $\mathbf{2 1 4 7}$ & $\mathbf{0 . 0 0 8 0}$ \\
\hline
\end{tabular}

Table 18 Percentage of obligors' variation with scaling factors smoothing considering both fixed and endogenous risk buckets

\begin{tabular}{rrrrrrr}
\hline & \multicolumn{3}{c}{ Fixed risk buckets } & \multicolumn{3}{c}{ Endogenous risk buckets } \\
\hline \multirow{2}{*}{ Sf_mean } & SF_max & \multicolumn{3}{c}{ Sf_mean } & SF_max \\
\hline & 100 & 100.00 & 98.44 & 100 & 99.99 & 97.74 \\
& 100 & 99.83 & 102.81 & 100 & 99.99 & 117.54 \\
& 100 & 101.81 & 282.42 & 100 & 100.12 & 138.37 \\
\hline \multirow{2}{*}{2007} & 100 & 98.50 & 96.91 & 100 & 97.75 & 96.20 \\
& 100 & 105.95 & 119.79 & 100 & 121.38 & 130.05 \\
& 100 & 354.96 & 538.22 & 100 & 153.38 & 209.60 \\
\hline \multirow{2}{*}{2008} & 100 & 98.56 & 96.90 & 100 & 97.75 & 96.29 \\
& 100 & 106.71 & 126.26 & 100 & 125.99 & 135.66 \\
& 100 & 348.11 & 499.81 & 100 & 146.12 & 197.87 \\
\hline \multirow{2}{*}{2009} & 100 & 101.34 & 100.00 & 100 & 102.05 & 100.00 \\
& 100 & 98.88 & 100.00 & 100 & 86.84 & 100.00 \\
& 100 & 39.64 & 100.00 & 100 & 71.16 & 100.00 \\
\hline 2010 & 100 & 100.61 & 99.24 & 100 & 101.01 & 99.18 \\
& 100 & 98.35 & 105.49 & 100 & 95.04 & 105.56 \\
& 100 & 66.11 & 128.71 & 100 & 76.83 & 114.48 \\
\hline 2011 & 100 & 100.14 & 98.59 & 100 & 100.15 & 98.48 \\
& 100 & 99.12 & 115.17 & 100 & 98.85 & 113.02 \\
& 100 & 93.91 & 141.74 & 100 & 97.18 & 125.05 \\
\hline 2012 & 100 & 100.45 & 98.65 & 100 & 100.38 & 98.71 \\
& 100 & 94.57 & 114.51 & 100 & 97.29 & 107.64 \\
& 100 & 92.24 & 129.16 & 100 & 93.54 & 123.57 \\
\hline
\end{tabular}

